\title{
Discussion on Some Topical Issues of Water Prevention and Control in Coal Mines
}

\author{
Shuning Dong ${ }^{1,2} \cdot$ Wenzhong Zhang ${ }^{1,2} \cdot$ Wanfang Zhou ${ }^{3} \cdot$ Rui Chai $^{1,2} \cdot$ Hao Wang ${ }^{1,2} \cdot$ Chunhu Zhao ${ }^{1,2}$. \\ Xingling Dong ${ }^{1,2} \cdot$ Qiangmin Wang ${ }^{1,2}$
}

Received: 25 September 2019 / Accepted: 13 March 2021 / Published online: 5 April 2021

(C) Springer-Verlag GmbH Germany, part of Springer Nature 2021

\begin{abstract}
Effective prevention and control of water hazards in China's coal mines require that several key issues be addressed. The key issues discussed in this paper are the complex and variable water inrush types in mines, uncertainties in calculation of mine inflow, and the primary mechanism of water hazards resulting from mining-induced bedding separation. Challenges encountered in reinforcement and grouting of the seam roof and floor are also discussed, as well as the risks posed by mine closure. We suggest research areas to better predict and understand the impacts of these issues and propose a direction for improvement of coal mine water control.
\end{abstract}

Keywords Water hazard prediction · Water hazard governance $\cdot$ Water inrush type $\cdot$ Mining-induced bed separation · Abandoned mine

\section{Introduction}

Coal mine water control involves multiple disciplines, including geology, hydrogeology, engineering geology, and mining engineering, and requires understanding of coal mining and related technology. Design of water control measures is continually evolving as coal mines become deeper and societal risk tolerance and regulations change. Discussed in this paper are four key issues regarding coal mine water control and management in China. The authors' hope that recognition of these key issues and the suggested solutions to them will help improve mine water control all over the world.

Wanfang Zhou

zhou_wanfang@yahoo.com

$\triangle$ Hao Wang

wanghao@cctegxian.com

Shuning Dong

dongshuning@cctegxian.com

1 Xi' an Research Institute of China Coal Technology and Engineering Group Corp, Xi' an 710054,

People's Republic of China

2 Shanxi Key Laboratory of Coal Mine Water Hazard Control, Xi' an 710077, People's Republic of China

3 Zeo Environmental, Knoxville, TN 37934, USA

\section{Calculation of Mine Water Inflow}

Calculation of mine water inflow is fundamental to mine water hazard prevention and control. The magnitude of mine water inflow is a major consideration in sizing drainage systems at all stages of a mine's life. Because of the complexity and diversity of hydrogeological conditions in different areas, there are many factors influencing mine water inflow, and these factors change steadily with external environmental conditions. Therefore, prediction of mine water inflow is a complicated and difficult task (Chen et al. 2009; Hua 2010). Analytical, numerical, and analogue methods are all commonly used in mine water inflow prediction.

The analytical method predicts mine water inflow based on the hydrodynamic principle of groundwater and well flow theory. Current practice includes the widely used 'big well method', in which the complex mining system is regarded as a big well with an equivalent radius, and the water inflow of the whole mining system is equivalent to the pumping rate of the big well (Wu et al. 2013).

The numerical method predicts mine water inflow by constructing a mathematical model consisting of discretized cells; this requires that the complex flow field be simplified into multiple relatively homogeneous seepage units (Chen and Tang 2014; Li et al. 2007). There are many proprietary 
numerical models that can be used to calibrate mine water level and flow data and predict mine water inflow.

The analogue method predicts mine water inflow of a mine using case histories from mines with similar geological and hydrogeological conditions ( $\mathrm{Hu} 2005$ ). If similar mines are found with long-term water inflow data, good correlation is assumed between the water inflow and influencing factors.

The analytical, numerical, and hydrogeological analogue methods all have some limitations. The big well method assumes conditions that differ from the conditions set up by the well flow theory. In the big well method, the equivalent radius of the well is based on the entire mining area, and the static reserve of the target aquifer in the mining area is not considered. In addition, the aquifer is assumed to be homogeneous.

In the numerical method, a great amount of data is required to describe the aquifer system of a study area. Challenges lie in identifying heterogeneous and anisotropic properties of the model domain and assigning appropriate boundary conditions. Because characteristics of the mining space change as mining progresses, the formation of waterconducting passages is usually not considered sufficiently (Hu and Yan 2016).

Application of the analogue method requires not only similarity in geological and hydrogeological conditions but also similar mining plans. Different mining plans can cause significant deviations in the calculated results.

For prediction of mine water inflow, attention should be paid to the following issues:

- Multiple elements including the hydrodynamic conditions that influence mine water inflow and the selected method must be considered simultaneously. The water source (e.g. porous medium or karst aquifer), geological structure, formation permeability, boundary conditions, and mining induced water-flow features must be considered so that the predicted inflow has a definite physical meaning.

- The prediction process must reflect the height of the overburden failure zone, the number of aquifers, the dimen- sion of the working face, the hydrogeological parameters, and how these change during different stages of the mining process. The predicted results must be able to provide the foundation for a scientific layout of the mine water drainage system.

- Predicted mine water inflow changes dynamically with the progress of underground mining, so predictions of mine water inflow need to address the time and location of possible mine water inrushes. These predictions and calculations inflow should be carried out by stage, level, and zone based on the mining plan and must be updated as the mine develops. The normal water inflow at different stages from construction period to production period in a mine is shown in Table 1 .

\section{Water Hazard Resulting from Mining-Induced Bedding Separations}

With increased mining depths, water hazards resulting from mining-induced bedding separations in the overlying formations have occurred in many large coal mining areas. Deformation or subsidence of the roof formation creates separation or additional void space between rock layers, which can fill with water. Water inrush from mining-induced bedding separation can be classified into three types, based on their cause: hydrostatic pressure, repeated disturbances, or hydrodynamic pressure. A hydrostatic pressure water inrush is triggered by the steady rise of the water level in the separated layer space. When the water level reaches a large enough height to damage the aquifuge (Cao 2013), this water drains through the water-conductive fractured zone, into the gob. When multiple seams are mined, repeated disturbance occurs, and multiple but connected water-conducting fractured zones develop. Repeated disturbance inrushes occur when the composite fractured zone connects the water-filled bedding separation voids.
Table 1 Prediction results of mine water inflow before production in a mine

\begin{tabular}{lll}
\hline Mine construction and production stages & $\begin{array}{l}\text { Predicted water } \\
\text { inflow }\left(\mathrm{m}^{3} / \mathrm{h}\right)\end{array}$ & $\begin{array}{l}\text { Accumulated time after } \\
\text { engineering beginning } \\
(\mathrm{d})\end{array}$ \\
\hline $\begin{array}{l}\text { Formation of shaft and shaft station } \\
\text { Formation of - 260 m horizontal main roadway and - 260 }\end{array}$ & 504 & 510 \\
$\quad$ to - 430 m sub-inclined shaft & 745 & 720 \\
Completion of preparation of first mining working face & 868 & 1010 \\
End of extraction of first mining working face & 900 & 1120 \\
Completion of preparation of second working face & 950 & 1300 \\
End of extraction of second working face & 1200 & - \\
Mine reaches designed production capacity & & \\
\hline
\end{tabular}


The hydrodynamic pressure water inrush (Su et al. 2003) is more complicated, and explains the actual inrush that occurred in the fully mechanized working face \#010201 of the Hongliu coal mine. Because the coal measures and the overlying coarse sandstone were obviously different in structure, strength, and deformation performance during mining, the layers separated in the lower strata. When the void between the separation layers filled with groundwater, a mining-induced water pool formed. As the void below the coarse sandstone grew in size, the overlying coarse sandstone became unstable and collapsed. The collapse resulted in an abrupt shock wave, which pounded the water body in the separation void, suddenly spiking the water pressure much higher. This water pressure spike broke through the remaining impermeable formation and caused the inrush.

Prevention and control of the three types of water inrush from bedding separation voids should focus on both analysis and study of hydrogeological conditions and the failure principle of composite beam and key layer. The following discrimination equation can be used to determine occurrence of bedding separations in the overlying formations:

$\mathrm{E}_{\mathrm{n}+1} \mathrm{~h}_{\mathrm{i}}^{3} \sum_{\mathrm{i}=1}^{\mathrm{n}} \gamma_{\mathrm{i}} \mathrm{h}_{\mathrm{i}}>\gamma_{\mathrm{n}+1} \sum_{\mathrm{i}=1}^{\mathrm{n}} \mathrm{E}_{\mathrm{i}} \mathrm{h}_{\mathrm{i}}^{3}$

For incompletely filled gob in the caving zone, the equation is:

$M-\sum\left(K_{i}-1\right) h_{i}>0$ where $E i, h_{i}$, and $\gamma_{i}$ are the elastic modulus, the thickness and weight of the $i$ th formation, respectively; $M$ is the thickness of the mined seam; $K_{i}$ and $h_{i}$ are the breaking and swelling coefficient and the original thickness of the $i$ th formation within the caving zone after coal extraction.

Equations (1) and (2) were applied to predicting the location of the separated layer in the overlying formations in working face 010201, and the calculated results matched the actual measurements. However, more research is needed on bedding separation water hazards, especially in the two following aspects:

- Dimension of the relatively stable "water-storing body" in the separated layers, as shown in Fig. 1: the beginning and ending locations of the separated layers decide the length of the water-storing body and provides the basis to correctly place dewatering boreholes so as to accurately pre-drain the water in the separation void, and eliminate the inrush threat.

- Mechanism of aquifuge reconstruction in separated layers: as observed in mining face 010201, mining was accompanied by roof caving, which resulted in layer separations in the overlying formation. Mine water inflow was normal until the mudstone aquifuge was exposed to water. As the mudstone particles filled the water-conductive fractures (a process similar to "aquifuge reconstruction"), the separated layers became a relatively stable water-storing space. Research on formation conditions, occurrence time, and position will provide the basis for accurate prediction of separated layer water hazards under these hydrogeological settings.
Fig. 1 Sketch of development characteristics and beginningending location of separated layer

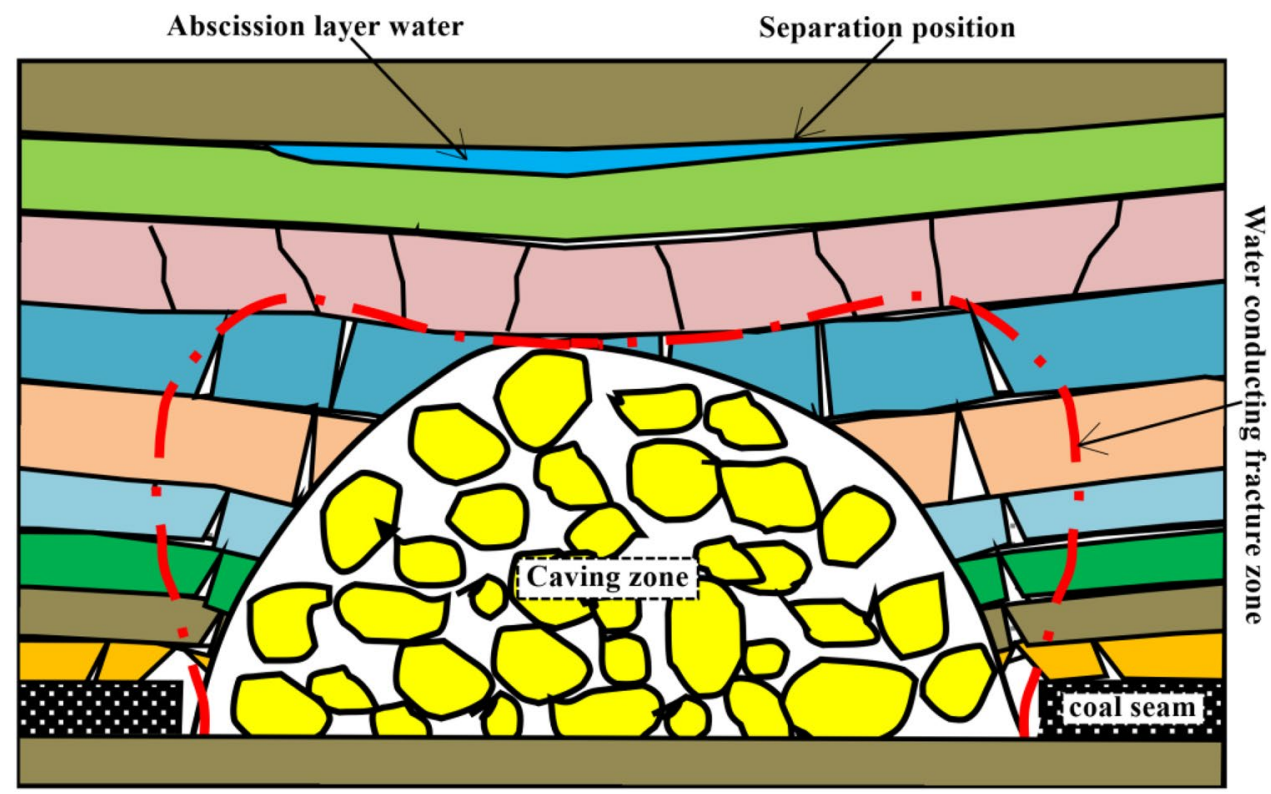




\section{Reinforcement and Reconstruction of the Coal Seam Floor}

In recent years, coal production in central and eastern China has shifted to deeper mining, averaging $10-25 \mathrm{~m}$ deeper a year. With the increased mining depth, the effective thickness of the aquifuge of the stope floor gradually approaches its bearable water pressure limit. Through analysis of the characteristics and the grouting effectiveness of boreholes in the Ordovician limestone of the Fengfeng Formation in the Dongpang Mine (Table 2), the following can be recognized:

- The upper $40 \mathrm{~m}$ of the Ordovician limestone of Fengfeng Formation was reconstructed by downward grouting (Nan 2010). After the first $20 \mathrm{~m}$ was reconstructed, the effectiveness of the grout diffusion and reconstruction the subsequent $20 \mathrm{~m}$ was verified.

- The test results indicated that the karst fractures of the upper aquifer of the Ordovician limestone were effectively grouted and that reconstruction by grouting was technically feasible.

- These grouting reconstruction tests in the Dongpang Mine provided important reference values for mining lower coal seams in other mines in the Hanxing mining area.

- Given that lower seam mining is threatened by the confined water of the Ordovician limestone and the demand for water-preservation mining in the deep mines in the Hanxing mining area, Zhao (2014) proposed a threedimensional grouting governance mode, which gives priority to in-advance regional surface grouting followed by supplemental underground reinforced grouting.

Governance of floor aquifers has been carried out mostly in single working faces or local structural zones. Local grouting in thin-bedded limestone aquifers in coal measures or independent reconstruction of the Ordovician limestone top is often limited in such areas and cannot accomplish the objective of in-advance regional control of the floor aquifer. Drilling through the huge Ordovician limestone aquifer and against the high water pressure in the aquifer has been

Table 2 Average flushing fluid consumption at different depth in Ordovician limestone top challenging due to inadequate underground horizontal directional drilling equipment. The following research should be carried out to overcome such challenges.

- Underground directional drilling and grouting equipment capable of drilling through hard rocks under high water pressure must be developed. To facilitate the in-advance regional aquifer reconstruction grouting, the following research and development are needed. Progresses on these fronts will provide technical support for underground in-advance regional treatment.

- Grouting vehicles with high pump pressure and large capacity.

- Hydraulic impact drill rig, screw stem for nearly horizontal drilling, and anti-impact high performance drilling bits for hard rocks.

- Efficient drilling technology for high water pressure environments, along with rapid trip-ins of multistage casing and casing cementing.

- Composite drilling technology, including control of technological parameters and trajectory of impact composite directional drilling.

- In-advance regional grouting reconstruction technology for limestone underlying coal seams is required. This includes:

- Conduct research on hydrogeological, engineering geological, surface and underground construction conditions for the floor limestone aquifer, as well as adapting in-advance regional grouting reconstruction to different conditions.

- Develop technology to control and track the trajectory of along-layer directional drilling to target grouting of the thin-bedded limestone of the Taiyuan Group and its undulating strata. The along-layer technology and dynamic lithological testing methods must be adapted to changing geological structures.

- Develop underground high-speed along-layer directional impact drilling technology to overcome technical difficulties such as slow drilling and low efficiency in hard rocks with high water pressure.

- Once these advances in drilling technology are realized, in-advance regional reconstruction models based on different aquifer conditions should be developed.

- Verification and evaluation technology for in-advance regional reconstruction of limestone strata below coal seams.

- Conduct extensive investigation and statistically analyze variations in water yield (leakage), grout- 
ing amount, grouting pressure, and specific water adsorption of boreholes in different strata.

- Develop methods to evaluate grouting reconstruction effectiveness, based on geophysical exploration results before and after grouting.

- Develop cross-hole radio penetrating apparatus and analyze the effectiveness of cross-hole grouting using cross-hole radio detection.

- Examine grouting effectiveness by drilling special holes to study the regional permeability of the grouted reconstruction area and develop water-intake rate evaluation criteria.

- Construct a technical support system for verifying and evaluating the effect of in-advance regional grouting reconstruction in a seam floor aquifer.

\section{Mine Closure}

Because of resource exhaustion, ground surface ecology, protection of water resources, and macro-adjustment of national policies, more mine closures have occurred in recent years in China. Hazards associated with abandoned mines include the following:

- Water drainage stops after mine closure, and the groundwater level rises, as shown in Fig. 2. The rising groundwater, if contaminated, can pollute the upper aquifers. This water may even reach the surface, causing pollution of surface water over large areas.

- Groundwater recharge can change hydrodynamic conditions and introduce other geological hazards. For example, groundwater recharge changes pore water pressure, which changes the effective stress in the gobbed areas. These changes can cause secondary subsidence in the once stable subsiding area. Because the mining spaces are once filled again with water, the rock pillars will be softened, damaged, and even collapsed, inducing geological hazards on the ground surface in mining area $(\mathrm{Hu}$ et al. 2002).

- Groundwater level rebound in abandoned mines results in water inrush in adjacent active mines. When the groundwater level rises to the underground workings that connect the adjacent mines, the groundwater will flow into the adjacent mines. The rising water level also increases lateral water pressure, which may break water barriers and cause water inrushes in adjacent mines (Zhao 2006).

Abandoned mines provide extra voids for water storage and are thus prone to inducing diverse environmental concerns. They may also function as a converging place of regional groundwater and a source of physical, chemical, and biological pollution of groundwater. Therefore, research should be carried out to:

- Understand the characteristics of groundwater movement and utilization of water resources in abandoned mines and induced environmental hazards after mine closure. The key is to analyze the characteristics of structure, distribution, and groundwater flow in the diverse water-bearing porosities of the abandoned mine system, particularly the characteristics of groundwater movement and circulation under conditions of coexistence of water-conducting channels, fractures and pores of different sizes, the relationship among storages, balance and conversion of groundwater in different media.

- Master the distribution and the mechanism of groundwater level rebounding and the mechanism and temporal evolution characteristics of the impact of polluted water in abandoned mines on the environment. Technology should be developed for prevention and control of environmental hazards possibly induced by abandoned mines. Regulations for mine closure should be in place to stipu-

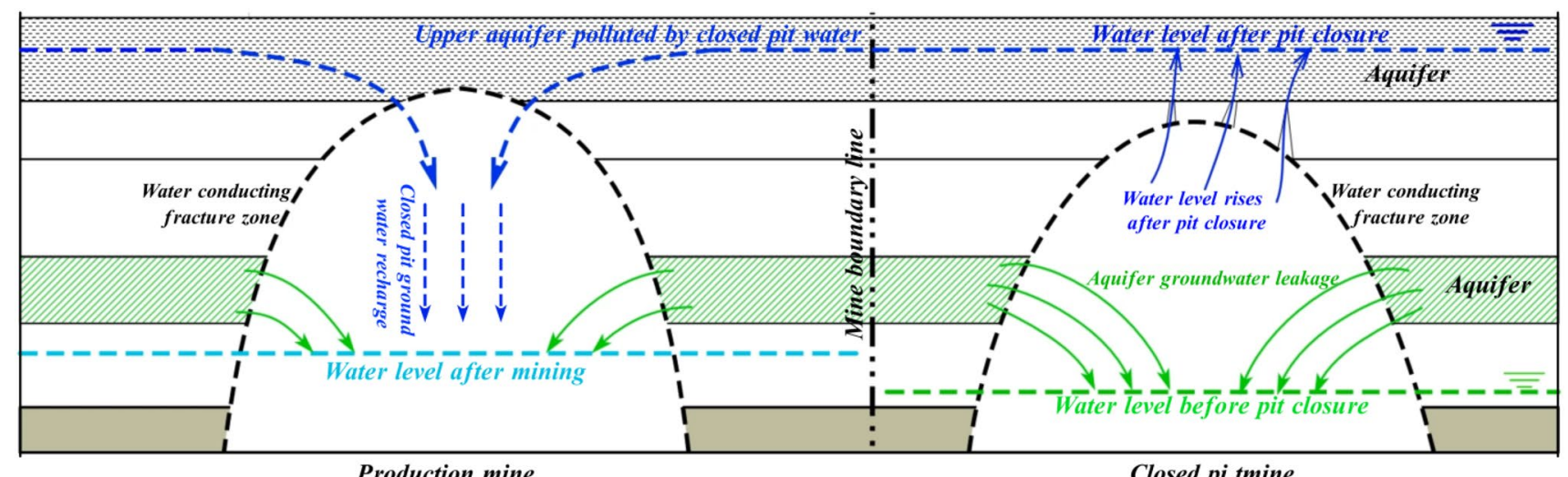

Production mine

Closed pi tmine

Fig. 2 Schematic change of water level in abandoned mine 
late measures of hazard prevention and mitigation during closure.

- Conduct groundwater monitoring in abandoned mines to determine the boundaries and hydrogeological conditions in abandoned mines. Water level, water quality, stress, strain, and resistivity are essential monitoring parameters in abandoned mines.

\section{Conclusions}

Significant advances have been achieved in recent years in China to increase the safety of mining operations. This paper discussed four key issues currently challenging coal mine water prevention and control: mine water inflow prediction, water inrush from mining-induced bedding separation, grouting to reinforce or reconstruct formations underlying or overlying coal seams, and environmental impacts of mine closure. The prediction of water inflow should be combined with the time and location of water inrush occurrence and mining progress.

There are three types of water inrush that result from mining-induced bedding separations. The lateral extent of mining-induced separated layers is proposed to be a key factor for accurate drainage of the separated layer water. The fracturing distance of these layers decides the beginning and ending locations of the separated layers. Based on the current research status on reinforcement and reconstruction of the roof and floor, we identified certain problems that should be urgently studied. These problems include low systematization of water hazard control technology and lack of efficient drilling equipment for the thick and hard Ordovician limestone aquifer.

Safety and environmental concerns are associated with mine closure. Research should be conducted on utilization of water resources in abandoned mines, but induced environmental hazards must be recognized. It is essential to understand the distribution of groundwater level, the nature of water table rebound and how this can cause contaminated mine water in abandoned mines to adversely affect the environment, along with the temporal evolution characteristics of water quantity and quality in abandoned mines.

Acknowledgement This study was financially supported by the National Key Research and Development Project of China (2017YFC0804100), and Science and Technology Innovation Fund of the Xi' an Research Institute of CCTEG (2018XAYZD11).

\section{References}

Cao DT (2013) Water inrush of hydrostatic pressure in separated layer and its control. Hydrogeol Eng Geol 40(2):9-12 (In Chinese)

Chen CX, Tang ZH (2014) Theoretic method of numeric simulation of groundwater flow and model design. Press of China Univ of Geosciences, Wuhan (In Chinese)

Chen MZ, Liu SC, Yang GY (2009) Development of prediction methods mine water inflow. Chin J Eng Geophys 6(1):68-72 (In Chinese)

Hu WY (2005) Theory and methods of mine water prevention and control. Press of Coal Industry, Beijing (In Chinese)

Hu WY, Yan L (2016) Analysis and thinking on mine inflow prediction. Coal Sci Technol 1(44):13-19 (In Chinese)

Hu WY, Li ZM, Wang CX (2002) Environmental geological hazards induced by abandoned mines. Coal Geol Explor 30(4):33-35 (In Chinese)

Hua JM (2010) Analytic method of unsteady flow for calculation of mine inflow. Coal Geol China 22(10):38-40 (In Chinese)

Li YF, Xu GF, Zuo CM (2007) Estimation of water inflow in Lianghuayuan mine. Coal Geol China 19(5):38-40 (In Chinese)

Nan SH (2010) Grouting and reconstruction technology for upper Ordovician limestone in Hanxing mining area. Coal Geol Explor 38(3):37-40 (In Chinese)

Su ZJ, Yu GM, Yang L (2003) Research on numeric simulation of mechanical mechanism of deformation of overburden separated layer. J Rock Mech Eng 22(8):1287-1290 (In Chinese)

Wu Q, Zhao SQ, Dong SN, Li JS (2013) Handbook of water prevention and control in coal mines. Press of Coal Industry, Beijing (In Chinese)

Zhao TC (2006) Comprehensive prevention and control technology of Ordovician limestone water in north China. Press of Coal Industry, Beijing (In Chinese)

Zhao QB (2014) Research and application of in-advance governance technology for areas with karst water hazards of Ordovician limestone. J Chin Coal Soc 39(6):1112-1117 (In Chinese) 